\title{
LibertaRian CRITIQUeS OF CONSENT IN SEXUAL OFFENCES
}

\author{
Stephen Knight
}

\begin{abstract}
This paper uses a system of moral principles derived from Alan Gewirth's Principle of Generic Consistency to demonstrate both the moral necessity of adopting a libertarian approach to consent in sexual offences, and that such an approach is practically superior with regard to the policy objectives which English law seeks to pursue in this field. The paper achieves this through inquiring into the state of contemporary English law and then analysing its political and philosophical underpinnings on a diverse range of issues, from uncomplicated consent through to coercion, informed consent, and the age of consent. In each case alternatives are proposed which would remedy the moral and practical deficiencies in English law. However, the paper concludes that remedying the defects in English law is only an interim solution, and that no true answer to the contradictions which the law faces is possible without a wholesale rejection of the socio-economic oppression which the greater part of humanity face under capitalism. In light of this, the author takes the view that the sexual autonomy of all agents can only be preserved through a transition to a libertarian and socialist society.
\end{abstract}

\section{A. INTRODUCTION}

The English law governing consent in sexual offences is torn between two conflicting ideologies. On the one hand we see a traditional, disapproving, and, above all, paternalistic ideology, often masquerading as 'morality', seeking to regulate sexual conduct and enforce traditional social norms. Counterposed to this approach is a more libertarian, free spirited ethic, which emphasises the importance of individual choice and of informed consent to sexual activities, so long as others are not hurt in the process.

This paper will seek to show how this latter libertarian approach is practically superior within the context of contemporary English society with regard to the practical aims which are agreed on by both approaches. Such practical aims include the reduction of sexual violence, the prevention of the exploitation of others, and, most importantly, the protection of an individual's physical integrity and autonomy. It will be suggested throughout that it is only through a system of law based on libertarian ideals that physical integrity and autonomy can truly be protected. 
The specific situations which will be examined are consent in general, acquiescence and coercion, informed and uninformed consent (for example where one person does not understand the nature and quality of the act), and consent where age is an issue. Where appropriate throughout the paper alternative ways to judge the presence or absence of consent, tailored to the requirements of relevant offences, will be proposed on the basis of both libertarian ideals and the practical aims which English law seeks to achieve.

Consent is a powerful, transformative concept, capable of rendering the immoral moral, the painful pleasurable, and the reprehensible commendable. Unsurprisingly then, consent plays an invaluable role in our system of law, transforming the illegal into the legal. However, for libertarians and particularly anarchists, the importance attached to consent, stemming from a desire to preserve individual autonomy, undermines traditional concepts of the state, and founds notions of a community built on free association.

At the forefront of ideas of consent is its central role in the concept of agency. Agents - practically reasonable people - are the central feature of all moral theories: as it relates to what should and should not be done, moral theorising is pointless with regard to anything which does not at least conceive of itself as acting for its own chosen (albeit not necessarily entirely, transcendentally, freely chosen) purposes, and which is not capable of determining its actions. The moral arguments set out in this paper rest on the moral theory of Alan Gewirth, the Principle of Generic Consistency (PGC). The argument to the PGC proceeds from the premise that an agent (A) must hold that their ends are (prudentially speaking) good for $\mathrm{A}$, and consequently that the means to their ends are also (instrumentally prudentially) good for A. ${ }^{1}$ There are certain means (freedom and well-being) which are necessary to all ends, and consequently A must hold these means to be categorically instrumentally good for A. From a prudential viewpoint then, A must hold that they ought to have freedom and wellbeing. ${ }^{2}$ For A to deny that they ought to have these rights would involve asserting that others may take them

\footnotetext{
${ }^{1}$ A Gewirth, 'The Epistemology of Human Rights' (1984) 1 (2) Social Philosophy \& Policy, 1, 15.

${ }^{2}$ ibid.
} 
away, thereby contradicting the previous step in the argument, and so A must claim rights to freedom and well-being. ${ }^{3}$ Since all agents share with A the same justificatory criterion for claiming rights to freedom and wellbeing, A must hold that every agent, by virtue of their agency, possesses rights to freedom and well-being. ${ }^{4}$

The PGC is of course not the only means of justifying reliance on non-consent as an important factor in sexual offences. Acceptance of the conclusions of this paper need not entail acceptance of Gewirth's argument to the PGC (or, indeed, any other argument to the PGC). However, without a basis in an undeniable premise and reasoning, the choice of a libertarian approach to issues of consent is no more than an individual preference. The use of the PGC allows us to proceed from the premise that individual autonomy is objectively valuable, and allows the performance of English law to be measured against an objective moral standard. Whereas other moral theories could be used to provide a basis for this argument, they would not have the same moral urgency that the necessary premise and reasoning of the PGC provide.

Gewirth characterises the generic right to freedom as consisting in 'noncoercion or non-interference by other persons, so that one's behavior is controlled by one's own unforced choice'. We might equally call this a right to autonomy. An individual's autonomy rights may be expressed as a positive right to do with themselves what they wish, so long as this is compatible with the rights of others, and therefore also a right not to have others interfere with this autonomy. ${ }^{6}$ Sexual autonomy rights can be derived directly from these autonomy rights: they are, in fact, not separate rights but a subset of them. Schulhofer has helpfully explained that sexual autonomy rights consist of two facets, the positive right to engage in activities with others, and the negative right to refuse sex for any reason or for none at all. ${ }^{7}$ Insofar as the law has a role to play, it involves

\footnotetext{
3 ibid 18 .

${ }^{4}$ ibid 18.

${ }^{5}$ A Gewirth, Reason and Morality (University of Chicago Press, 1978) 64.

${ }^{6}$ ibid 67.

${ }^{7}$ S Schulhofer, Unwanted Sex: The Culture of Intimidation and the Failure of Law (Harvard University Press, 1998) 99.
} 
preventing interferences with the generic rights (including rights to sexual autonomy), and helping individuals to attain them. ${ }^{8}$

\section{B. UNCOMPLICATED CONSENT}

In situations where issues of consent are not complicated by coercion, lack of information, intoxication, or legal fictions about the absence of consent, contemporary English law tends to give a straightforward definition of consent. For those offences which fall within the Sexual Offences Act 2003 (SOA 2003) including rape, sexual assault, and assault by penetration, a person is said to consent 'if he agrees by choice, and has the freedom and capacity to make that choice. ${ }^{9}$ Consent must of course 'be subsisting agreement at the relevant time. If what is relied on is a prior agreement to the act being done at a later time, there will not be consent if the agreement had been withdrawn before the act was done. ${ }^{10}$ The law's requirement with regard to consent is therefore one which requires free agreement, although not positive desire. For consent to be transformative, in that it renders that which would be an illegal act legal, it is only necessary for the consent to be to being the object of another's action, not to being one of the subjects of the action.

The requirement for consent to sexual relations in English law can only reasonably be attributed to a recognition on the part of policy makers, at least on some level, that individuals have genuine sexual autonomy rights, encompassing a right not to be subjected to unwanted sexual activities. Although there may be questions as to the historical basis for the recognition of such rights, particularly whether the rights were truly designed to protect individuals' (particularly women's) rights over their own bodies, it is unquestionably the case that this is the law's current preoccupation.

However, it may be considered a reflection of the paternalistic attitude that the law takes towards all autonomy rights that consent to being the object, rather than the subject, of sexual relations is what is considered transformative. Rather than requiring that, for individuals' bodies to be interfered with, they must in any way desire it, the law

\footnotetext{
${ }^{8}$ D Beyleveld and R Brownsword, Law as a Moral Judgment (Sheffield Academic Press, 1994) 159-164, 329.

${ }^{9}$ Sexual Offences Act 2003 s 74.

${ }^{10}$ R Card, Sexual Offences: The New Law (Jordans, 2004) 31.
} 
requires only that they allow that interference. The law thereby avoids taking the opportunity to promote the sexual autonomy of members of groups to whom such rights have been traditionally denied. The class of straight white men who construct and interpret law, being the socially dominant group, and being seen by the patriarchal society which they perpetuate as being sexually dominant, have little to gain by insisting that consent to sexual relations must be more than consent to being an object of another's sexual activities. However, as we shall see below, this position is difficult to escape from.

Where the law on consent manages to promote individuals' sexual autonomy rights, clearly libertarianism need add nothing. Consequently, the contribution of libertarianism in this field is likely to involve the creation of a state of affairs whereby each sexual partner is empowered to act not only as the object of the actions of others but also as the author of their own actions. A situation where individual agency is socially constructed so as to not make the individual desire the fulfilment of their own ends within sexual relations is intolerable from a libertarian perspective: society should encourage all participants to engage in sexual relations only when they are both willing and desirous of sexual relations in the circumstances.

However, if the law was to interfere in sexual relations in this area, by making the transformative nature of consent dependent upon individuals not merely participating in sexual relations in order to satisfy others' ends, but actively pursuing their own sexual desires, this would constitute an even greater intrusion on individual autonomy rights than would allowing people to engage in sexual activities as a mere object of them: to prevent someone making a free choice to become a mere object of sexual relations would be more paternalistic and anathema to libertarian ideals than the current legal concept of consent. Whereas there is a problem with social circumstance that encourage people to simply consent to being objects, it would be a far greater attack on their sexual autonomy to prevent them from consenting to being objects. Consequently, it would seem that a libertarian approach would be to encourage the social construction of agency in such a way as to make people wish to be the authors of their own sexual destinies; so long as an individual's agency was not constructed in such a way though, it would 
be anathema to libertarian ideals to reject the possibility of them meaningfully consenting to sexual relations as the simple object of another's desires.

\section{Coercion}

The borderline between submission and legitimate acquiescence amounting to consent in English law is unclear. As Sir Igor Judge stated in $R v$ Bree, 'Arguments about consent abound just because consent to sexual intercourse extends from passionate enthusiasm to reluctant or bored acquiescence, and its absence includes quiet submission or surrender as well as determined physical resistance against an attacker which might expose the victim to injury, and sometimes death. ${ }^{11}$ It is for this reason that there must be some attempt within the law to pin down consent's meaning. However, in light of the decision in $R v$ McAllister, ${ }^{12}$ one commentator has stated that, when summing up to a jury, a judge's reference to differences between consent and submission 'may only make things worse because the jury may (especially if they are a thoughtful jury) come back to ask what is the distinction; and then the judge has a real problem on his hands. ${ }^{13}$ In order to more easily understand the law, we will divide it into three areas: submission to threats, acceptance of inducements, and unequal power relationships.

It is evident from the judgment in McAllister that the pressure which may be applied to an individual in order to obtain apparent consent is ill-defined. Although before the Sexual Offences (Amendment) Act 1976 force, fear, or fraud were required to vitiate consent, ${ }^{14}$ the clearest statement of the law now comes from the judgement given in $R v$ Olugboja, that the jury 'should be directed that consent, or the absence of it, is to be given its ordinary meaning and if need be, by way of example, that there is a difference between consent and submission; every consent involves a submission, but it by no means follows that a mere submission involves consent'. ${ }^{15}$ Consequently, 'the dividing line in such circumstances between real consent on the one hand and mere submission

\footnotetext{
${ }^{11} R v$ Bree [2007] EWCA Crim 804,[2007] 2 All ER 676.

${ }^{12} R v$ McAllister [1997] Crim LR 233.

${ }^{13}$ T Rees, 'Sexual offences - indecent assault - consent' [1997] Crim LR 233-234.

${ }^{14}$ DPP v Morgan [1976] AC 182.

${ }^{15} R$ v Olugboja [1981] 3 All ER 443, 448.
} 
on the other may not be easy to draw'. The jury should also 'be directed to concentrate on the state of mind of the victim immediately before the act of sexual intercourse'.

Further to this, the SOA 2003 defines consenting as agreeing by choice, and having the freedom and capacity to make that choice. ${ }^{16}$ The Act also provides that where there is violence used or threatened towards the victim or another person there will be a presumption that consent was absent. ${ }^{17}$ However, immediate violence only accounts for a small section of the massive spectrum of possible means of coercion capable of inducing someone to submit to sexual relations. Although it has been argued that under the SOA 2003 many non-immediate threats would vitiate consent, ${ }^{18}$ the Act did not specifically require this change, leaving it up to a judiciary which has traditionally taken an extremely conservative approach to this subject. There has been no subsequent case law which suggests a modification to traditional interpretations, and so excluded from the Act, and from the case law, are violence threatened at a later date, economic threats (such as the threat of losing a job, eviction from a home, or threats to property), threats to a person's social standing, and even threats of leaving a partner, as well as many other threatening, coercive behaviours. The consequence of the law from Olugboja and the SOA 2003 is therefore that, whilst the individual's autonomy is protected by the law in certain cases of violence, there is little scope for juries to convict defendants for coercive behaviours which fall below this still exceedingly high threshold.

As Schulhofer has helpfully made clear, 'Threats represent a clearcut interference with autonomy. They are inherently coercive and illegitimate. [However, under] special circumstances, offers may have severe coercive effects, or they may be considered illegitimate for other reasons. ${ }^{19}$ Examples given by Wertheimer include:

Higher Grade. A, a professor, says "Have sexual relations with me and I will give you a grade two grades higher than you deserve. Otherwise you'll get just what you deserve."

\footnotetext{
${ }^{16}$ Sexual Offences Act 2003 s 74.

${ }^{17}$ Sexual Offences Act 2003 s 75.

${ }^{18} \mathrm{R}$ Card (n 10) 32.

${ }^{19}$ S Schulhofer (n 7) 118.
} 
Escape. B is in prison for life. A, a prison guard, offers to help her escape if she has sexual relations with him. ${ }^{20}$

Within English law, as far as offers and inducements are concerned, the decision in Olugboja and the SOA 2003 make clear that anything goes. From simple economic gains (e.g. prostitution) to clearly immoral offers which may be difficult to resist given the circumstances, in law positive inducements independent of any other considerations will never suffice to vitiate consent.

Within the field of unequal power relationships English law does little to protect the victim of sexual abuse by a person in a position of power over them. Certain laws of course exist to protect those physically incapable of consenting such as the mentally incompetent. ${ }^{21}$ Those in a position of trust over under-18s, such as teachers, will also find that they cannot obtain valid consent in law because of the unequal power relationship. ${ }^{22}$.

Outside of these areas, unequal power relationships - whether they are professional relationships such as doctor-patient or lawyer-client, economic relationships where one party is in an economically weak or dependent position, ${ }^{23}$ or any other relationship of unequal power such as that which may often exist in heterosexual relationships - never entail investigation into whether coercion vitiates consent.

In justifying contemporary English law in the field of coercion, Brooke LJ asserted in the case of $R v$ McAllister that 'The focus of the inquiry in all these cases is based on the sexual autonomy of the complainant. ${ }^{24}$ If this is truly representative of the motivation behind the law then libertarians would clearly see it as laudable. However, if we scratch the surface of this veneer of respect for individual autonomy we see a markedly different picture. In the very same passage Brooke LJ stated that 'the jury has to decide whether an alleged agreement to a sexual act may properly be seen as a real consent or whether it should be

\footnotetext{
${ }^{20}$ A Wertheimer, Consent to Sexual Relations (CUP, Cambridge 2003) 178.

21 Sexual Offences Act 2003 ss 30-42 create a large number of offences aimed at protecting people in such circumstances.

22 ibid. ss 16-19.

${ }^{23}$ For a good example from the USA, see R Cherry, 'Sexual Coercion and Limited Choices', in M Smith (ed), Sex without Consent: Rape and Sexual Coercion in America (NYU Press, 2001) 265-266.

${ }^{24} R v$ McAllister [1997] Crim LR 233, 233.
} 
regarded as a submission founded on improper pressure which this particular complainant could not reasonably withstand from this particular defendant.' The idea of there being 'proper pressure' - a necessary corollary of the idea of 'improper pressure' - and a requirement to resist a certain level of pressure would be anathema to libertarian thought: as Schulhofer has noted, 'When the person deploying the threat is clearly at fault in creating a dilemma, it seems odd that we sometimes blame the victim for not resisting. ${ }^{25}$

Instead of a desire to preserve individual autonomy, the policy underpinning the law in relation to acquiescence or submission appears as a simple desire to defend an outdated image of oppressive male sexuality and to 'give the benefit of the doubt to men who claim they mistook the woman's fear for awe and sexual interest ${ }^{26}$. Women (and it being almost always women is borne out by the volume of case law) are seen as acquiescing in, and accepting, sexual conduct even when it is plainly not wanted.

In devising a libertarian approach to coercion it is necessary first to understand why coercion is morally wrong. The reasoning used in this paper is based on the nature of coercion as interfering with a position in which agents have a moral right to find themselves. Where an agent (A) interferes with anything $(\mathrm{X})$ to which another agent $(\mathrm{B})$ has a moral right (e.g. to sexual autonomy), this interference is clearly immoral (as a breach of the $\mathrm{PGC}$ ). Where $\mathrm{B}$ has a moral right to two things ( $\mathrm{X}$ and $\mathrm{Y}$ ), to force B to choose between them (e.g. choose between sexual autonomy and not suffering violence) is also clearly immoral (as a breach of the PGC). Although this analysis may not allow us to demonstrate that coercion itself vitiates consent in the strongest sense, it does show that actions performed where ostensible consent is obtained through coercion are as morally repugnant as actions performed when consent is absent. Consequently, the law should treat situations where ostensible consent is obtained only through coercion as identical to those where consent is clearly absent.

The question of where to draw the line regarding the permissibility of threats has been discussed at length by Schulhofer and Wertheimer,

\footnotetext{
${ }^{25} \mathrm{~S}$ Schulhofer (n 7) 128.

${ }^{26}$ ibid 117.
} 
and both come to similar conclusions, that conduct which forces someone to choose between autonomy and a legally protected right should be seen as vitiating consent as far as the law is concerned. ${ }^{27}$ So long as the rest of the body of law in a society is in accordance with libertarian ideals, this proposal by Schulhofer and Wertheimer offers an attractive prospect for any attempt to promote individuals' autonomy rights. However, as we have noted, English law is emphatically not in accord with libertarian ideals. Insofar as improvements to contemporary English law are concerned, at a minimum it would be necessary for the libertarian to add that consent is vitiated when there is a breach of a natural duty to mutual aid (which is easily derived from the PGC since it imposes on all agents an obligation to respect and promote the freedom and wellbeing of all other agents), ${ }^{28}$ such as where an individual has it in their power to save another's life without causing undue harm to themselves or others, but only agrees to do so on the condition of receiving sexual services in return. A duty of mutual aid which is wide in scope of course flies in the face of any capitalist society where mutual aid is actively discouraged, ${ }^{29}$ and as with the protection envisaged by libertarianism of all moral rights, could most likely only exist as part of a wholesale social revolution. Where libertarianism is conceived of, in light of the PGC, as promoting autonomy of all kinds, not just the negative liberty which comes from excluding others, such a duty of mutual aid can arise.

As we have already noted, positive inducements may be just as coercive as threats. There may be a difference though between illegitimate offers and legitimate ones. As Schulhofer notes, 'When one person holds power over another, the offer to provide a benefit may mask an intent to inflict harm if the offer is refused. When this concern is present, the illegitimate offer closely approximates a threat in the classic sense. ${ }^{30}$ 'We usually sense that the target of a corrupt offer does risk injury if she turns it down, but the injury is more complex and intangible than in the case of a direct threat... the target of the demand is deprived of

\footnotetext{
27 ibid 132; A Wertheimer, (n 20) 184.

${ }^{28}$ A Gewirth (n 5) 217.

${ }^{29}$ For the active discouragement of mutual aid in capitalist societies see, for example, P Kropotkin, Mutual Aid: A Factor of Evolution (Dover Publications, 2006, originally published by Heinemann, 1902) 186-188.

${ }^{30}$ S Schulhofer (n 7) 140.
} 
'the right to impartial determination of the issue on the merits (i.e. whether to enforce the law...). ${ }^{31}$ It would therefore be appropriate for the law to treat such offers which mask an intent to inflict harm as vitiating consent.

The case of non-corrupt offers which do not mask an intent to inflict harm essentially reduces down to a trade of sexual services for benefits, whether economic or otherwise. For example, under the libertarian analysis we have identified, the 'Escape' situation quoted above would be considered a form of exchange. The archetype of this phenomenon is prostitution, and we can therefore use it as a helpful method to explore these issues. It is rare, although not at all unheard of, for people to choose to be sex workers where alternative employment is available. There is therefore, in an extremely large proportion of cases, a level of economic coercion at play in any sexual relations within the context of sex work. However, it would be strange if the economic coercion inherent in capitalist societies was only applied so as to deny an individual the capacity to consent to sexual relations, rather than to consent to any other act necessitated by that economic coercion. As Sullivan states, "why would we want to insist on the particular relevance of the liberal language of choice and consent in the area of sex work? If prostitution is to be judged according to liberal ideals of unimpeded choice and consent, why should factory work or commercial fruit picking not be judged in the same way? Of course, if these forms of work were judged according to similar criteria, it is likely that they might all be seen as coercive and as an impingement on human freedom'. ${ }^{32}$ As Morello has noted, 'the number one freedom that you and I have is the freedom to enter into a subservient role in the workplace... The only way you can avoid bosses and jobs is if you don't care about making a living. Which leads to the second freedom: the freedom to starve. ${ }^{33}$ Instead of denying people the right to make their own choices regarding whether to engage in sex work, 'a society that sought to enhance autonomy should first attempt to assure the availability of jobs not conditioned on sex, and an

\footnotetext{
31 ibid 141.

32 B Sullivan, "Prostitution and Consent: Beyond the Liberal Dichotomy of "Free or Forced"' in M Cowling and P Reynolds, (eds), Making Sense of Sexual Consent (Ashgate, Aldershot 2004) 128.

${ }^{33}$ CM Young 'Tom Morello: Artist of the Year interview' (Feb 1997) Guitar World.
} 
adequate safety net of welfare and child support for women unable to find work. ${ }^{34}$

It therefore seems that in order not to deny the capacity to consent (and the agency) of sex workers, any libertarian reform to the English law of consent in sexual offences should accept the right of sex workers to consent to sex even within conditions of capitalist oppression, just as any other worker may consent to various acts in the same context. However, it should also promote greater socio-economic equality in order to allow people to fully exercise their sexual autonomy rights. By extension, all non-corrupt positive inducements to sexual relations should be legally tolerated, but the conditions which compel people to enter into them where they would not do so in an ideal free society should not be tolerated.

Those unequal power relationships where one party is protected in English law do not deserve too much attention separate from consideration of the age of consent below. However, it might be suggested that the incapacity of under-18s to consent to sexual relations with teachers, etc. is in itself an unfair denial of their sexual autonomy rights. As related issues will be treated in greater depth later, we can simply assert that greater consideration should be given by our system of law to the possibility of the prohibiting of sexual relations between certain categories of people being an unjust denial of positive autonomy rights, and prosecutions should only be launched with the greatest of caution, and only where it is clear that apparent consent would not have existed were it not for the unequal power relationship. One issue which it is appropriate to treat in greater depth though is the unequal power relationship which some feminists believe exists between men and women.

In On the Subjection of Women, Mill first raised the issue of women being socialised to consent to sexual relations to which, without this process of socialisation, they would not consent. ${ }^{35}$ MacKinnon developed this argument further, arguing that patriarchal society itself is coercive, and that in patriarchal societies all heterosexual sex - and

\footnotetext{
${ }^{34}$ S Schulhofer (n 7) 165.

35 J S Mill, The Subjection of Women (Hackett, 1988, originally published in 1869) $15-16$.
} 
indeed much homosexual sex - amounts to rape. ${ }^{36}$ Women are socialised in such a way as to make consent to sexual relations meaningless, this meaninglessness of consent being due in part to the unequal power relations between men and women in contemporary society. Although it has been roundly criticised on practical and empirical grounds by feminists and non-feminists alike, ${ }^{37}$ MacKinnon's argument is nonetheless extremely compelling and, if correct, would need to be absorbed into any libertarian view of consent as being based on autonomy and free choice.

However, MacKinnon's argument that patriarchal society is so coercive as to prevent women from making free choices ignores the fact that the agency of women in patriarchal society is in fact shaped by that very society. When considering agency we should not imagine that all humans are entirely transcendentally free actors or that they are unaffected by social influence. Although societal factors inevitably shape an individual's development, what they develop into is not a creature which is incapable of acting autonomously. The individual shaped by societal factors has the same capacity for agency as the agent who springs into existence with her mental faculties fully formed. It is merely the ends which the agent seeks to pursue, and the way they pursue these ends, which social conditioning of an agent affects, not the existence of their agency itself. MacKinnon is effectively arguing that women's decision making processes are destroyed by patriarchal society, and therefore that they are rendered incapable of consenting, as if the particular way an agent's personality is constructed negates all capacity.

Consequently, if we are to treat agency as the criterion for consenting to sexual relations, women in a patriarchal society have as strong a capacity to consent as in a society which recognises no gender binary at all. Although we should clearly aim at the development of a society which does not systematically oppress women (or enforce a gender binary), within a libertarian analysis of the law on consent in contemporary English society it is wrong to view women as incapable of giving consent to sexual relations.

\footnotetext{
${ }^{36} \mathrm{C}$ MacKinnon, Toward a Feminist Theory of the State (Harvard University Press, 1989) 174, 178.

${ }^{37}$ See eg, A Wertheimer (n 20) 189.
} 


\section{INFORMED CONSENT}

As previously mentioned, s 74 of the SOA 2003 states that 'a person consents if he agrees by choice, and has the freedom and capacity to make that choice.' As a starting point, this appears fairly neutral as between libertarianism and paternalism, perhaps even favouring libertarianism with its requirement that a person not only agrees, but 'agrees by choice'. Having the 'freedom and capacity to make that choice' could coherently be interpreted so as to require that, in order to have a capacity to make a choice, a person must have all relevant information available to them regarding that choice. However, it has not been interpreted in this manner. We will consider here four ways in which ostensible consent may be uninformed: on the basis of who the person is; what the act is; the consequences of the act and a partner's lies about future intentions; and whether there is a risk of pregnancy or STI transmission.

Arguably the strongest assault on the right to informed consent was made by $R v$ Barrow $^{38}$ wherein it was held that where a woman was deceived into believing that someone was her husband this did not vitiate her consent to sex with that person. This point of law was controversial at the time and was contradicted in the Irish case of $R v$ Dee; the Criminal Law Amendment Act $1885 \mathrm{~s} \mathrm{4}$, which was declaratory of the common law, ${ }^{39}$ supported the position that ostensible consent obtained by impersonating a husband was not consent. However, the overruling only applied to a woman who was fraudulently induced to believe that a man was her husband, rather than any other man. In $R v$ Elbekkay ${ }^{40}$ it was held that restricting the absence of consent to impersonations of husbands was no longer legally sound. This position was reaffirmed by SOA $2003 \mathrm{~s}$ $76(2)$ (b) which creates a conclusive presumption that where ostensible consent is obtained by 'impersonating a person known personally to the complainant' there is no consent.

\footnotetext{
${ }^{38} R v$ Barrow (1865-72) LR 1 CCR 156.

39 J C Smith, 'Rape - consent obtained by impersonation of boyfriend' [1995] Crim LR 163, 164.

${ }^{40} R v$ Elbekkay (Court of Appeal, Criminal Division, McCowan L.J., Sachs and Mitchell JJ,, 12 September 1994) reported by Richard Percival and (CA) discussed in Smith, ibid, 163-165.
} 
Fraud as to the nature of a sexual act has long been held to vitiate consent. In the $19^{\text {th }}$ century case of $R v$ Flattery $^{41}$ it was held that where sexual intercourse was falsely presented as a surgical operation, consent did not exist to the intercourse. This was confirmed in $R v$ Williams $^{42}$ where sexual intercourse was represented as an act to improve a girl's breathing. It is therefore clear that, where the nature and quality of an act is misrepresented, despite consent to the action itself, consent will not be treated as present in English law.

Where consent is predicated on some event which will happen at a later date (for example marriage, or payment for services rendered) English law takes a lack of intention on the part of the promisor to fulfil their promise as being no barrier to the promisee's consent being viewed as genuine. In $R v$ Linekar $^{43}$ for example it was asserted that a promise to pay for sex which the defendant had no intention of keeping was no barrier to valid consent. In such a case where ostensible consent was obtained by false pretences there was, before the introduction of the SOA 2003, an offence under Sexual Offences Act 1956 s 3. However, no offence is now committed.

The case of $R v$ Devonald $^{44}$ is somewhat incongruous with the existing case law. The case, involving a man inducing a 16 -year-old boy to masturbate over a webcam whilst encouraging the boy to believe that he was a 20 -year-old woman interested in a sexual relationship, saw the defendant convicted on the basis that the victim was 'deceived as to the purpose of the act of masturbation'. Although the nature and quality of the act were known by both parties to be sexual, the purpose of the act was different from that which the boy believed. It is somewhat difficult to reconcile this with the existing jurisprudence regarding false pretences, and it may well mark a new, more autonomy-rights-focussed approach to this aspect of consent. Alternatively, it may simply mark a judicial desire for condemnation on the specific facts of the case.

Related to the issue of the nature and quality of an act, is the question of whether an uncommunicated risk of pregnancy or sexually transmitted disease, known to the defendant, vitiates consent. In the $19^{\text {th }}$

\footnotetext{
${ }^{41} R v$ Flattery (1877) 2 QBD 410.

${ }^{42} R v$ Williams [1923] $1 \mathrm{~KB} 340$.

${ }^{43} R v$ Linekar [1995] QB 250.

${ }^{44} R v$ Devonald [2008] EWCA Crim 527.
} 
century case of $R v$ Clarence $^{45}$ it was held that failing to explain the risk of having an STI did not vitiate consent, even where consent would not be forthcoming if there was knowledge of the risk of STI transmission. Recently, the Court of Appeal stated in unequivocal terms that 'Where one party to sexual activity has a sexually transmissible disease which is not disclosed to the other party any consent that may have been given to that activity by the other party is not thereby vitiated. ${ }^{46}$

The phrase 'informed consent' may seem tautologous - how, it may be asked, can meaningful consent be given when someone does not know what they are consenting to? - but from what we have just seen, this position is not uniformly reflected in English law. Whereas libertarianism holds that consent must be fully informed in order to be valid, the conservative sees only ostensible consent in the mind of the person consenting, at the time of the act consented to, and to the narrowly-defined physical act, as important. It is this latter, conservative outlook which again characterises English law. The tendency to deny a right to all relevant information before sexual activity is consented to is a clearly conservative one, opposing full recognition of a right to bodily integrity, the most likely victims of this in contemporary English society of course being women. Rarely, if ever, is this philosophically motivated: 'good reasons are seldom offered for the law's refusal to protect sexual autonomy from even the most egregious deceptive inducements. ${ }^{, 47}$

As well as this conservative underpinning of the law in this field, there is also an undeniable desire, at least to some extent, to preserve individual autonomy by punishing those whose attacks on individual autonomy rights are too heinous for our society to countenance. This is reflected for example in the prohibition on deceiving a partner as to identity, or to the actual nature of the act itself. Consequently, the law seems somewhat inconsistent. In one variety of circumstances the law accepts that an action may be in law non-consensual because of the intention which lay behind the act, of which the victim was uninformed (for example, sexual intercourse represented as medical treatment). In another set of cases, and seemingly without providing rational

\footnotetext{
${ }^{45} R v$ Clarence (1889) LR 22 QBD 23.

${ }^{46} R v B$ [2007] 1 WLR 1567. See also on this point $R v$ Dica [2004] 3 All ER 593.

${ }^{47} \mathrm{~S}$ Schulhofer (n 7) 112.
} 
justification, the court refuses to accept that sexual activities were in fact non-consensual because of the intention behind the act, of which the victim was uninformed (for example, sexual intercourse where the continuance of a relationship is promised without an intention on the part of the promisor to carry on the relationship).

It is clear therefore that conservative elements of the judiciary, denying the need for meaningfully informed consent in many circumstances, would regard consent in many instances as valid where it is indisputably uninformed. What's more, the conservative attitude towards informed consent does not merely stop at denying an individual's right to autonomy on the basis of being in full receipt of all relevant information: it regularly stretches as far as to permit a victim to be deliberately misinformed - outright lied to even - whilst still asserting that this fails to vitiate consent to sexual activities. Once again, the primary losers in this ideological battle are of course women. In a patriarchal society like ours where male sexuality is equated with aggressive dominance over others, and particularly over women, ${ }^{48}$ it is hardly surprising that an overwhelmingly conservative and male judiciary and legislature would seek to support a man's right to exert his dominance over women through deception.

Much of the defence of the conservative approach relies on an attempt to distinguish fraud in the inducement from fraud in the factum. Wertheimer demonstrates the fallacy in this with the following example:

Odometer. A sets back the odometer on a car before selling it to B. We do not say that there is no criminal fraud in Odometer because B is not averse to buying this nominal car from $A$, that it is a mere case of fraud in the inducement. No, it is serious fraud precisely because A misrepresents the characteristics of the car. ${ }^{49}$

This demonstrates the corrupt logic employed by defenders of the present system. Since the inducement is so often as essential to the creation of consent as the act itself, in focussing only on the physical acts, rather than the intentions of the parties, the court deprives victims of redress for breaches of their physical autonomy.

\footnotetext{
${ }^{48}$ On the patriarchal nature of contemporary Western societies, see for example $\mathrm{M}$ Wykes and K Welsh, Violence, Gender \& Justice, (London: Sage 2009) 102-104.

${ }^{49}$ A Wertheimer (n 20) 196.
} 
The libertarian attitude towards informed consent stands in stark contrast to this approach. Wertheimer observes that 'A's deception should generally undermine the moral and legal transformative power of consent because it precludes $B$ from being able to decide whether engaging in sex with $\mathrm{A}$ is in her interests or compatible with her values. ${ }^{50}$ Schulhofer adds that 'A person can be autonomous only if she has mental competency, an awareness of her options, and sufficient information to be able to choose intelligently between the possibilities that external conditions make available. ${ }^{51}$ Consequently, in denying B sufficient information to choose intelligently, whether by lies or omission, A interferes with B's sexual autonomy rights.

Given that the libertarian approach to consent serves to better protect individual autonomy and the right to bodily integrity, how might this be put into practice in English law? A simple amendment to the statutory provisions would suffice, stating that consent is not present where ostensible consent is only obtained by deception, whether through positive acts such as lies or through omissions. The defendant would then need to know (or believe, or reasonably believe as appropriate) that consent was not present on this basis.

Wertheimer suggests that, although it may be undisputed that it is morally wrong when sexual relations take place when B's informed consent is absent and $\mathrm{A}$ is aware of this, there may be certain problems, particularly relating to evidence, and the requirement to ensure that convictions are safe, when we turn to declaring such relations legally wrong. ${ }^{52}$ However, it is difficult to see that a jury of 12 reasonable people would find any great problem with understanding and adjudicating on the proposed libertarian test. This test would certainly not reduce the number of convictions for sexual offences, and would be equally certain to increase the number of convictions for sexual offences where the victim only gave ostensible consent on the basis of deception or the withholding of information.

\footnotetext{
50 ibid 193.

${ }^{51} \mathrm{~S}$ Schulhofer (n 7) 105.

${ }^{52}$ A Wertheimer (n 20) 199.
} 


\section{E. Age OF CONSENT}

Whereas those elements of sexual consent which we have examined so far are focussed for the most part on limitations of negative autonomy rights, the age of consent, presents a striking example of limitations of positive autonomy rights, and therefore merits detailed examination. The peculiarity of this element of the law regarding sexual consent has led to a great number of rationalisations being developed for why individuals of a certain age should not be recognised as having a capacity to consent to sexual activities. Many of these defences are detailed, and prima facie reasonable, and therefore deserve an equally detailed examination and response.

English law maintains a legal fiction regarding the capacity of under-16s to consent to sexual relations: whether or not an individual does in fact consent to sexual relations, English law holds that any consent is vitiated by the fact of the individual's age. The SOA 2003 s 9 created the offence of 'sexual activity with a child':

A person... (A) commits an offence if -

(a) he intentionally touches another person (B),

(b) the touching is sexual, and

(c) either-

(i) $\mathrm{B}$ is under 16 and $\mathrm{A}$ does not reasonably believe that $\mathrm{B}$ is 16 or over, or

(ii) $\mathrm{B}$ is under 13 .

Ss 10-12 of the same Act create offences in the same terms with regard to 'causing or inciting a child to engage in sexual activity', 'engaging in sexual activity in the presence of a child', and 'causing a child to watch a sexual act'. These are typical of the law's treatment of under-16s, and it is these offences and their pre-2003 predecessors that will be discussed below.

A minimum age of consent to sexual activity has existed in English law since at least $1275 .^{53}$ The age of consent for girls to heterosexual sexual intercourse was originally set at 12 years, and was raised to 13 in $1875,{ }^{54}$ then later to 16 in $1885 .^{55}$ The age of consent for all other

\footnotetext{
53 Policy Advisory Committee on Sexual Offences, Working Paper on the Age of Consent in relation to Sexual Offences (HMSO, London 1979) 4.

${ }^{54}$ Offences Against The Person Act 1875.

${ }^{55}$ Criminal Law Amendment Act 1885.
} 
'indecent' activities for girls ('indecent' of course having a narrower definition than 'sexual', which may apply to acts such as kissing which are not indecent ${ }^{56}$ ) and for all 'indecent' activities for boys, was set at 16 in $1922 .{ }^{57}$ Unsurprisingly, the minimum age for male homosexual sexual activities has historically been substantially different from that for heterosexual sexual activities: when certain male homosexual acts were decriminalised in $1967^{58}$ the age of consent was set at 21, and it was later reduced to 18 by the Criminal Justice and Public Order Act 1994. Parity was finally achieved between the ages of consent for homosexual and heterosexual acts with the passage of the Sexual Offences Amendment Act 2000. The recent SOA 2003 reinforced this state of affairs, with 16 being the minimum age to consent to any sexual activities.

The reasons given in support of an age of consent are manifold, and whilst the great majority are clear examples of paternalism motivated by a belief that young people are incapable of making decisions for themselves, or should be deprived of the opportunity to do so, there are some reasons which, whether for philosophical or purely pragmatic reasons, seem to provide justifications for an age of consent and will therefore be examined in some detail. The Working Paper on the Age of Consent in relation to Sexual Offences produced by the Policy Advisory Committee on Sexual Offences ${ }^{59}$ (PAC) in 1979 usefully articulates many of these reasons.

It should be noted that the context of the PAC's discussion of the heterosexual age of consent was one of 'protecting girls' from exploitation by boys and men, rather than protecting young people from exploitation by those in a position of power over them. The idea that a girl (or woman) could take advantage of a boy (or man) was unambiguously rejected by the context of the debate. The justifications given by the PAC for the age of consent at 16 are:

1. Girls may suffer physical harm, either from pregnancy at a young age or from damage resulting from abortion harming their chances of having a child later in life;

\footnotetext{
${ }^{56} \mathrm{R}$ Card (n 10) 13.

${ }^{57}$ Criminal Law Amendment Act 1922.

${ }^{58}$ Sexual Offences Act 1967.

${ }^{59}$ Policy Advisory Committee on Sexual Offences (n 53) 6-13.
} 
2. Girls may suffer psychological harm;

3. Girls may have their education damaged;

4. A girl's sexual development may be detrimentally affected;

5. Immature choice is not free choice;

6. Legal certainty is required as to when a person is capable of giving valid consent; and

7. Prosecutorial discretion is sufficient to mitigate any harshness of age of consent laws.

In addition to these justifications for an age of consent at 16, we may add the influence of certain LGBT activists and groups who have desired the creation of a form of 'hegemony of equality at 16': as a marginalised social group the LGBT community has sought to reinforce 16 as the age of consent for all, and to attach their claim for equality to this established social norm. ${ }^{60}$ Our $8^{\text {th }}$ justification - not endorsed by the PAC - may therefore be that the age of consent is a useful practical tool in terms of advancing equality between straight and gay people.

Let us now expose the problems inherent in each of these arguments. According to Waites, in using justifications 1 to 4, 'The committee thus drew upon problematically medicalised understandings of adolescence and sexual health. These arguments, invoking biological factors in opposition to a lowering of the age of consent, asserted physiological constraints upon the possibilities for young women's choice and agency, rather than exploring the possibility of promoting the social conditions and availability of resources for young women to make informed choices. ${ }^{61}$ Inasmuch as the age of consent is justified on these grounds it is therefore clearly problematic; the idea that capacity to consent is based on the hypothetical negative consequences of sexual relationships, rather than the existence of the ability to understand those consequences, may be used to deny that agency is ever the key to capacity to consent. This in turn serves to deny the utility of consent itself, as consent exists in law as a means by which to promote the autonomy which is characteristic of agency. As a side-note, arguments relating to pregnancy cannot of course be used to deny capacity to boys -

${ }^{60} \mathrm{M}$ Waites 'The Age of Consent and Sexual Consent' in Cowling, Mark \& Reynolds, Paul (eds), Making Sense of Sexual Consent (Ashgate, Aldershot 2004) 80. ${ }^{61}$ ibid 77. 
or to girls in a homosexual relationship - under the post-2003 regime with its allusions to sexual equality.

Further arguments may be given against justifications 1-4 on purely practical grounds, although unfortunately, due to constraints of space, cannot be considered here.

With regard to the argument that 'immature choice is not free choice', it is not in contention that where immaturity is a genuine limit to autonomous agency, or the capacity to understand certain necessary information, this should be reflected in law. However, immaturity itself is no barrier to freedom of choice. Not having yet achieved physical, psychological or sexual maturity does not render a choice un-free: the vast majority of decisions made by young people, from deciding what to eat to deciding whether to obey the law (as we shall see shortly) are generally conceived of as free decisions, so long as the individual involved is aware of all the relevant information and has the ability to reason freely on that basis. In this light, it is rather anomalous that choices regarding sexual consent are automatically seen as un-free, when our society explicitly recognises that immaturity is not incompatible with agency.

Justifications 6 and 7, when viewed together, pose a rather large problem - it is highly contradictory to assert that the law must be both certain and open to prosecutorial discretion. The PAC was, of course, right to call for certainty in the law, but where this certainty comes at the expense of justice, it is entirely worthless. As we shall see below, the certainty of the law produces considerable injustice. As for the argument given by the PAC that the large number of cautions handed out by police is evidence that the law is not problematic, it can be countered that it is contrary to the rule of law to enact Draconian laws and then leave it to guidelines which have no force in law to mitigate those laws. ${ }^{62}$ Good law simply does not rest on prosecutorial discretion: if the discretion can be exercised by police or prosecutors, it can equally well be written into the law.

Our $8^{\text {th }}$ justification based on a hegemony of equality at 16 is harder to contest. It does appear that there is in fact such a hegemony in existence, although whether it in fact benefits equality is questionable.

${ }^{62}$ R Card (n 10) 11. 
The aspects of an inequality of an age of consent which perpetuate homophobic bigotry of course could only exist so long as the age of consent itself exists: without an age of consent, no bigotry stemming from an unequal age of consent would be possible.

The paternalistic considerations underlying the age of consent are further and equally convincingly demonstrated by the social pressures behind the development and retention of age of consent laws. In $19^{\text {th }}$ century England the desire for age of consent laws was primarily motivated by the Social Purity movement which sought to impose stricter so-called 'moral' controls on sexuality, and also by the desire to prevent child prostitution. ${ }^{63}$ The boundary of 16 was chosen as 'an age below which women were seen as requiring protection, rather than at an age at which they achieved the ability to make their own decisions. ${ }^{64}$ Women were treated as little more than chattels, the property, in turn, of their father, and then their husband. ${ }^{65}$ The law was therefore concerned with protecting a woman's value by punishing perceived breaches of sexual morality through sex outside of marriage, rather than with protecting her autonomy. As a result, the age of consent was clearly determined 'with little reference to capacities for decision-making competence. ${ }^{66}$

If the reasoning behind age of consent laws was originally at base merely an enforcement of women's submissive role in society, have subsequent developments in the law changed this fact? The approach taken by the PAC marked a shift in thought with regard to justifications of the age of consent. It indicated that 'the age of 16 represented an age of psychological maturity marking the attainment of decision-making competence' rather than a point at which a girl needed protecting from immorality. ${ }^{67}$ Nevertheless, the language of the committee was still deeply marked with sexism, with its portrayal of girls as in need of protection from predatory men. ${ }^{68}$ The approach of the PAC was to provide a whole new, yet equally flawed, rationale for the existing age of consent.

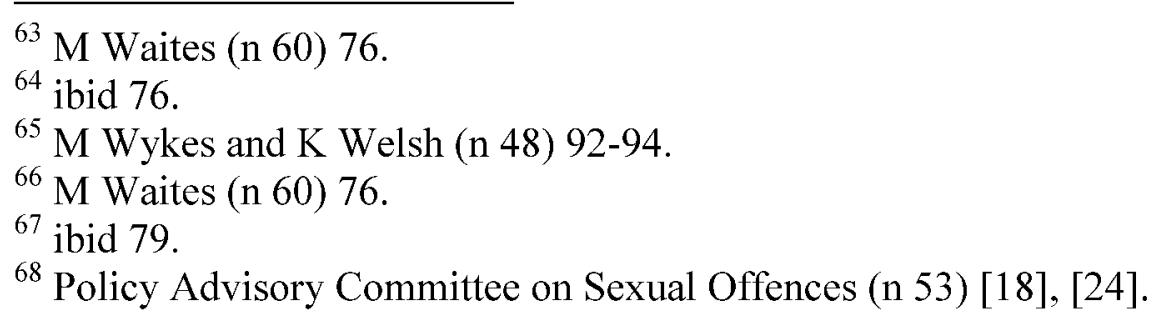


This rationale for the existing age of consent has not been seriously reinvestigated by lawmakers since the $\mathrm{PAC}$ report. The debate around the SOA 2003 conspicuously avoided a reconsideration of the age of consent. ${ }^{69}$ Taub and Schneider allege that, despite any change in rationalisations given for age of consent laws, the original, patriarchal and patronising reasons still underlie them. Such laws 'have rested historically on the legal fiction that young women are incapable of consent. They exalt female chastity and reflect and reinforce archaic assumptions about the male initiative in sexual relations and the weakness and naïveté of young women. ${ }^{, 70}$ It is easy to see why one might consider this still to be the case: given that they were propagated in the $19^{\text {th }}$ century and then reinforced in the late $20^{\text {th }}$ century under sexist - if not misogynistic - auspices, it can safely be assumed that the theoretically and practically poor arguments discussed above remain the basis for rationalisations of the age of consent.

Even if those reasons invoked in defence of the age of consent are without merit, there may still be other reasons providing a persuasive argument in favour of retaining an age of consent. It is therefore appropriate to analyse the negative practical consequences of an age of consent in our society, in order to show why its replacement is necessary. The first and possibly most important negative aspect of the age of consent is its supreme futility: inasmuch as it is intended to discourage young people from sexual activities, it is entirely ineffective. According to recent research, "A quarter of women and nearly a third of men in the 16-44 age group had heterosexual sexual intercourse under 16. The median age for first sexual activity was 14 for girls and 13 for boys. ${ }^{, 71}$ Indeed, only $31 \%$ of $11-16$ year olds considered sex under 16 'always wrong ${ }^{, 72}$, and of those in Y11 (aged 15-16) only $22 \%$ thought it 'always wrong ${ }^{, 73}$. Of course, the mere breach of a law does not render it

\footnotetext{
${ }^{69}$ M Waites (n 60) 74.

${ }^{70} \mathrm{~N}$ Taub and E Schneider 'Women's Subordination and the Role of Law' in DK Weisberg (ed.) Feminist Legal Theory (Temple University Press, Philadelphia 1993) 18 .

${ }^{71}$ First and Second National Surveys of Sexual Attitudes and Lifestyles (Penguin 1994, and in The Lancet (2001), vol 358, 1843) cited in R Card (n 10) 10.

${ }^{72} \mathrm{~S}$ McGrellis, S Henderson, J Holland, S Sharpe, and R Thomson Through the Moral Maze a quantitative study of young people's values (Tufnell, 2000) 11.

${ }^{73}$ ibid 14.
} 
inequitable or deserving of repeal. However, according to Lord Millet, in consequence of the flagrant disregard shown by society to the age of consent it 'has long since ceased to reflect ordinary life, and in this respect Parliament has signally failed to discharge its responsibility for keeping the criminal law in touch with the needs of society. ${ }^{, 74}$ The effect of the age of consent is then to treat those young people involved in mutually supportive and loving relationships as serious criminals, deserving not of society's support, but of conviction for sexual offences which carry with them a lifelong stigma. Many young people are inevitably dissuaded from seeking help and advice, including contraception, where they fear that they or their partner may be prosecuted as a result. ${ }^{75}$ The law also clearly interferes with the sexual autonomy rights of young people: as agents they have the same rights to sexual autonomy as older agents - any increased legal protection they may require currently comes at the expense of outright denial of their autonomy rights. As Schulhofer has noted, 'Respect for autonomy requires protecting our freedom to refuse sexual contact, but it also requires protecting our freedom to seek emotional intimacy and sexual fulfilment with willing partners. Stringent safeguards that fully protect sexual autonomy for one person can easily destroy it for another. ${ }^{76}$

As a principle, the age of consent also suffers from its arbitrariness. Through the desire to draw a 'line in the sand' the law creates the fundamentally absurd situation of a person being considered incapable of consenting one day, due to their age, and then capable of consenting the next, having passed a developmental milestone at the stroke of midnight on their $16^{\text {th }}$ birthday. In fact, the law explicitly recognises that development is gradual, and that people do gain the capacity to consent to sexual relations before the age of 16: offences such as sexual activity with a child would be charged as rape, assault by penetration, or sexual assault (all requiring non-consent) if consent was not present. If this line in the sand was drawn equally throughout the world there would at least be some reason behind it, but even within cultures almost identical to Britain's own there are differences within ages of consent: ' 15 in

\footnotetext{
${ }^{74} R v K$ [2001] UKHL 41 [44].

${ }^{75} \mathrm{R}$ Card (n 10) 11.

${ }^{76} \mathrm{~S}$ Schulhofer (n 7) x.
} 
Denmark, France and Sweden, 14 in... Italy, and 13 in Spain. ${ }^{77}$ It is consequently clear that the choice of a particular age of consent is arbitrary, criminalising blameless conduct in a futile bid to prohibit some blameworthy conduct which could be criminalised more safely in other ways.

One of the most striking problems with age of consent laws is that they are incongruous with laws on criminal responsibility. As Barbaree and Marshall have put it, 'For the victim below the age of consent, the law regards the individual to be 'incapacitated' by her or his immaturity, lacking the psychological resources to make the autonomous decisions regarding sexual behaviour. In contrast, the perpetrator of the same age is not viewed as being incapacitated. He or she is held to be fully responsible for the criminal sexual behavior. ${ }^{78}$ How, if a person is incapable of understanding sex so as to consent to sexual relations, are they able to understand it sufficiently to be convicted of sexual offences? This conceptual issue is closely linked with a serious practical problem, that under-16s are made victims by the criminal justice system which ostensibly sets out to protect them. This clearly demonstrates a severe problem with regards to the aims which the law seeks to achieve in this field: it is incapable of respecting the autonomy and human dignity of those under the age of consent who engage in consensual sexual relations, and it catastrophically fails as far as the protection of minors from harm is concerned: the harm arising from criminal conviction is far greater than the harm averted through preventing consensual sexual relations amongst those under a set age. Even where there is no criminal conviction, the harm arising from police investigations into a child's personal life is inevitably considerable. ${ }^{79}$ The consenting partner of someone who is prosecuted may also become 'a victim in reality as well as in law'. 80

The law also provides a method by which parents, disapproving of their children's sexual choices, can attempt to enforce their choices on the child by reporting the child's partner to the police. This may be of particular concern to gay children, whose parents, if possessed of a

\footnotetext{
${ }^{77} \mathrm{R}$ Card (n 10) 9.

${ }^{78} \mathrm{H}$ Barbaree, and W Marshall The Juvenile Sex Offender (Guilford, 2006) 13.

${ }^{79} \mathrm{R}$ Card (n 10) 11.

80 D West 'The Victim's Contribution to Sexual Offences' in J Hopkins (ed) Perspectives on Rape and Sexual Assault (Harper \& Row, 1984) 5.
} 
disapproving 'morality', may wish to punish their children's partners. This objection is therefore of particular relevance to those in the LGBT community who wish to create a form of 'hegemony at 16 '.

Catherine MacKinnon can give us one final and powerful critique of the age of consent:

The age line under which girls are presumed disabled from consenting to sex, whatever they say, rationalizes a condition of sexual coercion which women never outgrow. One day they cannot say yes, and the next day they cannot say no. The law takes the most aggravated case for female powerlessness based on gender and age combined and, by formally prohibiting all [underage] sex as rape, makes consent irrelevant on the basis of an assumption of powerlessness. This defines those above the age line as powerful, whether they actually have power to consent or not. ${ }^{81}$

Libertarians accept that society owes those who have not yet reached the age of reason, a special degree of protection: it is an essential component of liberty that one should not be forced into action which one does not will, and if one is incapable of reasoning in a particular sphere so as to develop an intention, then anything that one is forced to do will inevitably not be in accordance with one's will. It is this protection of those incapable of giving consent which forms the one aim of age of consent laws which is shared by libertarians. On a practical level then, how can we reframe English law with libertarian considerations in mind?

An investigation into an alleged victim's genuine capacity to consent would allow for those people below a certain age who are in clear need of protection to be protected, but would also extend protection further, to those victims of sexual abuse who are over the current age of consent and yet who do not have a capacity to consent, whether through late development, mental trauma, or senility. Such a scheme would rid the law of all those negative aspects of the age of consent identified above, and would have the further advantage of allowing investigation not only into whether apparent consent existed, but also into whether any form of exploitation vitiating consent took place.

In cases where capacity to consent is at issue due to a complainant's age, juries could be asked to consider a series of factors

$\overline{{ }^{81} \text { C MacKinnon (n 36) 175-176. }}$ 
related to whether an individual genuinely is capable of consenting to sexual relations. Ryan has helpfully articulated several issues which we may appropriate for such a test:

In any sexual interaction, the factors that are useful when assessing the presence or absence of exploitation are equality, consent, and coercion. Equality considers differentials of physical, cognitive, and emotional development, passivity and assertiveness, power and control, and authority... Consent: agreement including all of the following: (1) understanding what is proposed based on age, maturity, developmental level, functioning, and experience; (2) knowledge of societal standards for what is being proposed; (3) awareness of potential consequences and alternatives; (4) assumption that agreement or disagreements will be respected equally; (5) voluntary decision; (6) mental competence... Coercion... refers to the pressures that deny the victim free choice. The factors already discussed as inequality are often the tools of coercion. ${ }^{82}$

It has been argued by Card that such a system would create a risk 'that a youngster will have to go through the trauma of giving evidence, and being cross-examined, about exploitation or coercion or lack of understanding, [and of] trials getting bogged down over such issues (or prosecutions being dropped in such cases because of the risk of this happening)'. ${ }^{83}$ However, he concludes that this does not pose an insurmountable obstacle, and is a small price to pay for a just system of law. It has also been unconvincingly argued that a case by case assessment of competence to consent would be impractical, implying that a jury would be incapable of deciding whether an individual child, in specific circumstances, was capable or not of consenting. ${ }^{84}$ However, this claim is absurd. In cases where a complainant lacks capacity for reasons independent of their age, jurors currently have to take into account the same sort of considerations as they would with young complainants, and there is no suggestion that they are incapable of doing so. Furthermore, a juror stands a far greater chance of determining whether an individual was capable of giving valid transformative consent than a legislator stands of determining when entire populations on average gain the capacity to give valid consent to sexual relations (given that this may not,

\footnotetext{
${ }^{82}$ G Ryan 'Sexually Abusive Youth: Defining the Problem' in G Ryan and S Lane (eds) Juvenile Sexual Offending (Jossey-Bass, San Francisco 1997) 4-5.

${ }^{83} \mathrm{R}$ Card (n 10) 11.

${ }^{84}$ A Wertheimer (n 20) 222.
} 
and most likely will not, be at the end point of the individual's cognitive evolution). It is submitted that, under the alternative to age of consent laws proposed, it would be extremely unusual for a jury not to convict someone for the sort of morally repugnant abuse from which age of consent laws aim to protect young people.

It should also be noted that this change to age of consent laws has the advantage of preserving the advantages inherent in the 'hegemony of equality at 16': LGBT youth would not face the reinforcement of discrimination which was previously an element of unequal age of consent laws.

\section{F. CONCLUSION}

Throughout this paper we have seen that a paternalistic ideology has historically pervaded the law, systematically denying many individuals their right to sexual autonomy. It is only in the past few decades that libertarian ideas have begun to seep into the law. There remains a long way to go if the libertarian ideal is ever to be achieved: the promotion of individual freedom must not only be accepted as a primary aim of the law, but society as a whole must support this with meaningful economic equality and the elimination of an oppressive gender binary; coercion in sexual relations will never be effectively criminalised without eliminating coercive social structures; and it would be entirely futile to attempt to promote the sexual autonomy of every individual whilst existing social institutions fight against the recognition of the general autonomy rights of the greater part of humanity. Although the apparent impossibility of resolving these issues under capitalism cannot alone justify the comprehensive transformation of society, it is nonetheless difficult for this author to conceive of the achievement of the reforms set out in this paper without wholesale libertarian and socialist revolution. 